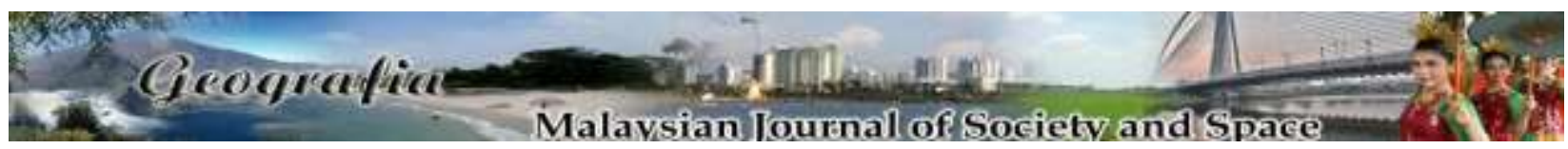

\title{
Pengintegrasian sosial: Sejauhmana hubungannya dengan kesihatan diri, keagamaan dan jaminan pekerjaan dalam kalangan orang kena pengawasan
}

Fauziah Ibrahim, Wan Shahrazad Wan Sulaiman, Ezarina Zakaria, Mohammad Rahim Kamaluddin

\author{
Pusat Kajian Psikologi dan Kesejahteraan Manusia, \\ Fakulti Sains Sosial \& Kemanusiaan, Universiti Kebangsaan Malaysia \\ Correspondence: Fauziah Ibrahim (email: ifauziah@ukm.edu.my)
}

Received: 06 September 2019; Accepted: 01 August 2020; Published: 28 August 2020

\begin{abstract}
Abstrak
Pengenalpastian faktor yang mempunyai hubungan dengan aspek pengintegrasian sosial dalam kalangan bekas penagih yang telah tamat menjalani program rawatan dan pemulihan merupakan aspek penting dalam usaha negara menyediakan formula tentang kejayaan pemulihan. Oleh itu kajian ini dilakukan bertujuan untuk (1) mengenalpasti tahap pengintegrasian sosial dalam kalangan Orang Kena Pengawasan (OKP) dan (2) menganalisis hubungan antara kesihatan diri, jaminan pekerjaan dan keagamaan dengan pengintegrasian sosial dalam kalangan OKP. Kajian telah dijalankan dengan menggunakan reka bentuk tinjauan keratan-lintang secara kuantitatif. Seramai 218 bekas penagih dadah yang telah tamat menjalani program pemulihan di Cure and Care Rehabilitation Centre (CCRC) dan kini sedang menjalani pengawasan oleh Agensi AntiDadah Kebangsaan (AADK) dipilih sebagai responden kajian. Data kajian dianalisis secara deskriptif dan inferensi dengan menggunakan ujian Korelasi Pearson. Analisis kajian deskriptif menunjukkan pengintegrasian sosial dalam kalangan OKP berada pada tahap yang baik iaitu tinggi (60.1\%). Manakala analisis inferensi pula mendapati bahawa faktor kesihatan diri, jaminan pekerjaan dan keagamaan menunjukkan hubungan yang positif dan signifikan dengan pengintegrasian sosial dalam kalangan OKP. Hasil kajian memberi implikasi positif terhadap usaha penambahbaikan program pengintegrasian sosial yang dijalankan terhadap OKP oleh pihak yang berkepentingan. Penekanan terhadap aspek keagamaan, kesihatan diri dan jaminan pekerjaan perlu diambil kira dalam menentukan kejayaan pengintegrasian sosial dalam kalangan OKP.
\end{abstract}

Kata kunci: jaminan pekerjaan, kesihatan diri, keagamaan pengintegrasian sosial, orang kena pengawasan. 
GEOGRAFIA Online ${ }^{\mathrm{TM}}$ Malaysian Journal of Society and Space 16 issue 3 (135-146)

(C) 2020, e-ISSN 2682-7727 https://doi.org/10.17576/geo-2020-1603-11

\title{
Social Integration: How It Relates to Personal Health, Religious and Employment Security among Individuals on Surveillance
}

\begin{abstract}
Identifying factors related to aspects of social integration among former addicts who have undergone treatment and rehabilitation programs is an important aspect of the nation's efforts to provide formula for successful recovery. Therefore, this study was conducted to (1) identify the level of social integration among OKPs and (2) analyzed the relationship between personal health, religious and employment security with social integration among the OKPs. Study was carried out using a cross-sectional quantitative survey. A total of 218 former drug users who successfully discharged from Cure and Care Rehabilitation Centre (CCRC) and under surveillance by the National AntiDrug Agency (AADK) were selected as respondents. The data was analyzed using descriptive and inferential statistics. Descriptive analysis shows that social integration among the OKPs is at a high level (60.1\%). Meanwhile, inferential analysis identified that personal health employment security and religious shows a positive and significant relationship with social integration among the OKPs. The findings have implications for various stakeholders. Emphasis on religious aspects, personal health and employment security should be considered in determining the success of social integration among OKPs.
\end{abstract}

Keywords: employment security, personal health, religious, social integration, individuals on surveillance

\section{Pengenalan}

Pengintegrasian sosial merupakan satu proses yang mendorong seseorang individu dalam usaha menyesuaikan diri dengan keadaan persekitaran sosial yang lebih luas tanpa berhadapan dengan isu stigma dan pelabelan (Leverents, 2011). Shinkfield et al., (2009) dan Smallbone at al., (2013) pula berpandangan apabila seseorang individu merasakan bahawa dirinya dihargai dan diterima oleh individu lain maka ikatan kasih sayang yang kuat akan terjalin antara mereka. Keadaan ini memudahkan proses pengintegrasian sosial serta membantu pesalah/banduan untuk menjadi sebahagian daripada anggota masyarakat tanpa dibelenggu dengan masalah stigma atau sterotaip. Dalam kajian ini pengintegrasian sosial merujuk kepada dorongan, penerimaan, penglibatan dan rangkaian hubungan yang baik berdasarkan daripada tiga dimensi iaitu individu (OKP), keluarga dan masyarakat setempat bagi membolehkan OKP menyesuaikan diri dengan kehidupan baru dan keadaan persekitaran sosial di sekelilingnya.

Di Malaysia, jumlah OKP yang berada di bawah perkhidmatan pemulihan AADK menunjukkan peningkatan ketara daripada aspek bilangannya iaitu sejumlah 64,559 orang pada tahun 2017 berbanding 46, 139 orang pada tahun 2015 (Maklumat Dadah, 2017). Angka yang kian bertambah ini menunjukkan lebih ramai bekas penagih yang telah menjalani rawatan dan pemulihan dibebaskan dengan pengawasan. Kesemua mereka ini dilihat sedang berusaha untuk membina kehidupan baharu, ingin mengekalkan kepulihan dan sedang berusaha untuk mengintegrasikan diri dengan keadaan persekitaran dan masyarakat sekeliling. OKP yang diselia oleh Pegawai Pemulihan kebiasaanya perlu mematuhi syarat-syarat perintah pengawasan dalam 
tempoh dua hingga tiga tahun dengan mengambil kira komitmen kehadiran klien terhadap program pemulihan yang dijalankan (Maklumat Dadah, 2017). Zarina, Nor Azizan dan Mohamad Daus (2015) mendapati tidak ramai dalam kalangan OKP menunjukkan kepatuhan mengikuti program pengawasan yang dikendalikan oleh pihak AADK. Usaha OKP untuk membebaskan diri daripada belenggu dadah bukan sahaja memerlukan kekuatan dan semangat juang pulih yang tinggi malah perlu mendapat sokongan daripada ahli keluarga dan masyarakat sekeliling agar proses pengintegrasian sosial mereka berjaya dilaksanakan. Manakala kajian yang dijalankan oleh Mohd Alif et al., (2018) mendapati penghijrahan bekas banduan berlaku disebabkan oleh kelemahan proses pengintegrasian sosial antara bekas banduan yang telah keluar daripada institusi Penjara dengan keluarga dimana hubungan yang tidak mesra antara keluarga dengan bekas banduan menyebabkan mereka melakukan penghijrahan dan tinggal secara berasingan dan bersendirian tanpa sokongan daripada ahli keluarga.

Terdapat beberapa kajian yang berkaitan dengan pengintegrasian semula. Antaranya kajian yang dijalankan oleh Tharshini et al., (2018) terhadap pesalah muda yang sedang menjalani hukuman Perintah Khidmat Masyarakat di bawah pengawasan Jabatan Kebajikan Masyarakat. Hasil kajian beliau mendapati majoriti tahap pengintegrasian sosial (67.3\%) bagi pesalah muda berada pada tahap sederhana sahaja. Dapatan kajian mereka dilihat memberi implikasi terhadap keperluan pihak yang berkepentingan untuk merangka dan menambahbaik modul dan program-program pemulihan ke arah meningkatkan tahap konsep kendiri, kesedaran komuniti, sokongan sosial dan pengintegrasian sosial bagi pesalah muda di Malaysia. Manakala kajian yang dijalankan oleh Tharshini \& Fauziah (2018) terhadap faktor-faktor pelindung yang menyumbang ke arah pengintegrasian semula banduan yang berjaya melalui pendekatan kajian secara ulasan sistematik dengan menggunakan pangkalan data Elsevier dan Sage mendapati terdapat empat faktor utama yang menyumbang ke arah pengintegrasian semula banduan yang berjaya iaitu: (i) faktor motivasi untuk berubah, (ii) faktor sokongan sosial, (iii) faktor pegangan keagamaan dan (iv) faktor pekerjaan. Manakala kajian yang dijalankan oleh Uggen (2000) dan Ezarina et al., (2016) mendapati peluang dan jaminan pekerjaan juga memainkan peranan penting ke atas kejayaan kepulihan pengintegrasian semula banduan an bekas penagih ke dalam masyarakat. Ini kerana pekerjaan berfungsi sebagai kawalan sosial dan membolehkan bekas banduan dan bekas penagih menyesuaikan diri dengan kehidupan selepas bebas dari penjara serta memberi perubahan terhadap identiti diri mereka (Uggen, Wakefield, \& Western, 2005). Manakala Bracken, Deane dan Morrissette (2009) mendapati pegangan agama yang baik membantu banduan untuk berubah ke arah kehidupan yang lebih baik dan dapat menyesuaikan diri dengan masyarakat sekitar. Amalan agama dalam kalangan banduan memberi orientasi yang positif terhadap transformasi kognitif dan perubahan emosi yang positif. Akhirnya, perubahan ini berupaya menggalakkan tindakan pro-sosial yang boleh membantu mengelakkan daripada terjebak semula dengan jenayah dan menjadikan proses pengintegrasian semula mereka ke dalam masyarakat berjaya (Giordano, Longmore, Schroeder, \& Seffrin, 2007).

\section{Kajian Literatur}

Model Pengintegrasian Sosial: Kajian lanjutan yang dijalankan oleh Irwin (1970) telah berjaya memperkenalkan satu model yang dinamakan sebagai pengintegrasian sosial. Menurut Irwin (1970) pengintegrasian sosial merupakan satu proses yang bertujuan untuk meningkatkan dan menguatkan hubungan antara individu dengan persekitaran sosial. Ia adalah sebahagian daripada 
GEOGRAFIA Online ${ }^{\mathrm{TM}}$ Malaysian Journal of Society and Space 16 issue 3 (135-146)

(C) 2020, e-ISSN 2682-7727 https://doi.org/10.17576/geo-2020-1603-11

proses yang mendorong seseorang individu untuk menyesuaikan dirinya dengan persekitaran sosial yang lebih luas tanpa berhadapan dengan isu stigma dan pelabelan (Irwin, 1970). McNeill (2014) menjelaskan bahawa seseorang individu boleh berjaya dalam proses pengintegrasian sosial sekiranya; (i) wujud perubahan positif dalam tingkah laku individu, (ii) wujud perubahan dalam identiti individu dan (iii) individu merasakan bahawa diri mereka adalah sebahagian daripada komuniti pro-sosial. Selain itu, Fox (2016) menyatakan bahawa kesungguhan individu untuk menyesuaikan diri dengan persekitaran sosial serta kesediaan anggota masyarakat untuk menerima individu yang pernah terjebak dengan salah laku jenayah tanpa sebarang stigma dan diskriminasi mampu membantu menjayakan proses pengintegrasian sosial. Setiap individu yang pernah ditempatkan di penjara mempunyai pengalaman, keperluan, dan kemahiran baru yang akan dibawa kembali apabila kembali semula ke dalam komuniti (Waleed, 2010). Pengalaman menjalani hukuman di penjara memberi peluang kepada individu tersebut untuk berubah dan mengubah tingkah laku serta pemikiran negatif yang wujud dalam diri mereka serta menguatkan lagi hubungan dengan ahli keluarga selepas dibebaskan daripada penjara (Waleed, 2010). Oleh yang demikian, Eva et al., (2013) menjelaskan bahawa fasa pengintegrasian sosial bagi individu yang pernah ditempatkan di penjara adalah satu proses yang dinamik serta memerlukan motivasi dan sokongan yang berterusan daripada rangkaian sosial yang terdapat dalam sesebuah komuniti.

Pengintegrasian Sosial-Keluarga: Menurut Fox (2015), pengintegrasian sosial merupakan satu proses yang kompleks kerana bekas penagih dadah perlu; (i) membina dan menggekalkan identiti diri yang positif, (ii) menjalin hubungan yang baik bersama ahli keluarga serta (iii) berusaha untuk mengelakkan diri daripada terlibat semula dengan perlakuan yang bertentangan dengan norma sosial. Manakla hasil kajian yang dijalankan oleh Travis et al., (2003) pula mendapati bahawa sokongan padu daripada ahli keluarga merupakan aspek penting bagi individu yang baru dibebaskan daripada penjara kerana penerimaan positif dan sokongan emosi yang diberikan oleh ahli keluarga mampu menyumbang ke arah proses pengintegrasian sosial yang berjaya serta mengelakkan individu terbabit daripada terlibat semula dengan penyalahgunaan dadah. Sokongan sosial daripada ahli keluarga merupakan dimensi penting dalam pengintegrasian social. Cullen (1994) dalam kajiannya mendapati bahawa sokongan dan motivasi yang diberikan oleh ahli keluarga mampu; (i) meningkatkan tanggungjawab dalam diri individu, (ii) mewujudkan interaksi yang positif antara individu dan ahli keluarga, (iii) mewujudkan ikatan kasih sayang antara individu dengan ahli keluarga serta (iv) menguatkan kemahiran daya tindak dalam diri individu. Gomez et al., (2010) pula menjelaskan bahawa individu yang kurang menerima sokongan daripada ahli keluarga akan mula berasa sunyi dan keseorangan serta wujud perasaan dipinggirkan oleh orang lain. Manakala Lopez et al., (2014) dan Juan et al., (2017) pula berpandangan sokongan dan motivasi yang rendah daripada ahli keluarga mendorong seseorang individu untuk terlibat semula dengan aktiviti jenayah yang seterusnya menjejaskan proses pengintegrasian sosial mereka ke dalam masyarakat.

Pengintegrasian Sosial-Komuniti: Menurut Grommon (2013), Law et al., (2013) dan Connolly et al., (2017) penglibatan individu dengan kesalahan penyalahgunaan dadah merupakan penghalang utama kepada pengintegrasian sosial kerana individu terbabit dianggap telah menjejaskan ketenteraman dan keselamatan orang awam yang menimbulkan persepsi negatif anggota masyarakat terhadap diri mereka. Secara amnya, apabila seseorang bekas penagih dadah dibebaskan daripada penjara atau mana-mana institusi pemulihan mereka akan berhadapan dengan dunia realiti yang penuh dengan cabaran kerana diri mereka akan dipandang rendah dan dipinggirkan oleh anggota masyarakat. Apabila keadaan ini berterusan ia sememangnya akan menjejaskan motivasi dan semangat individu tersebut untuk meluaskan jaringan sosial dengan 
GEOGRAFIA Online ${ }^{\mathrm{TM}}$ Malaysian Journal of Society and Space 16 issue 3 (135-146)

(C) 2020, e-ISSN 2682-7727 https://doi.org/10.17576/geo-2020-1603-11

ahli komuniti di sekelilingnya (Dodge \& Pogrebin, 2001). Oleh yang demikian, menurut Jacobs (2013), elemen 'civil disposition' adalah penting untuk berjaya dalam proses pengintegrasian sosial dimana ahli komuniti masih perlu menghormati individu yang pernah terlibat dengan perlakuan yang bertentangan dengan norma sosial agar masalah pelabelan dan stigma dapat dielakkan. Pengintegrasian sosial yang berjaya menyebabkan individu merasakan bahawa diri mereka adalah sebahagian daripada ahli komuniti serta berpeluang untuk terlibat dalam interaksi yang bersifat normatif dengan anggota masyarakat bagi mengelakkan perasaan keterasingan sosial (Wong \& Solomon, 2002). Menurut Gracia dan Herrero (2004), penerimaan positif daripada persekitaran sosial mampu membina jaringan sosial yang kuat antara individu dengan anggota masyarakat serta mewujudkan perapatan dengan ahli komuniti agar proses pengintegrasian sosial berjalan dengan lancar. Selain itu, Dodge et al., (2001) dan Scroggins (2012) menjelaskan bahawa ketersedian rangkaian sosial dalam komuniti seperti peluang pekerjaan yang tetap, sumber kewangan yang stabil dan kawasan kediaman di tempat yang berisiko rendah mampu memudahkan proses pengintegrasian sosial bagi bekas pesalah/banduan/penagih dadah.

Memandangkan aspek pengintegrasian sosial merupakan perkara penting untuk membantu bekas penagih yang telah dirawat untuk pulih dan bebas daripada dadah, maka kajian ini dijalankan untuk mengenalpasti tahap pengintegrasian sosial dalamkalangan OKP yang telah tamat menjalani program rawatan dan pemulihan di Institusi. Kesemua mereka kini sedang menjalani program pengawasan di dalam komuniti dan dibawah pengawasan pihak Agensi AntiDadah Kebangsaan (AADK). Kajian ini juga menganalisis perhubungan antara aspek kesihatan diri, jaminan pekerjaan dan keagamaan dengan pengintegrasian sosial. Di Malaysia tidak banyak kajian yang menumpukan aspek pengintegrasian sosial dalam kalangan orang kena pengawasan. Oleh itu kajian ini dijalankan bertujuan untuk; (1) mengenalpasti tahap pengintegrasian sosial dalam kalangan OKP dan (2) menganalisis hubungan antara kesihatan diri, jaminan pekerjaan dan keagamaan dengan pengintegrasian sosial dalam kalangan OKP. Dalam kajian ini, tiga hipotesis kajian telah dibina seperti berikut:

1. Tidak terdapat hubungan yang signifikan antara kesihatan diri dengan pengintegrasian sosial dalam kalangan OKP.

2. Tidak terdapat hubungan yang signifikan antara jaminan pekerjaan dengan pengintegrasian sosial dalam kalangan OKP.

3. Tidak terdapat hubungan yang signifikan antara keagmaan dengan pengintegrasian sosial dalam kalangan OKP.

Hasil kajian diharap dapat menyumbang kepada bidang ilmu pengintegrasian social dan keperluan pembinaan modul serta program-program pengintegrasian sosial yang dikendalikan oleh pihak berkepentingan. Hasil kajian secara empirikal ini juga diharap dapat dimanfaatkan oleh pihak kaunselor, ahli psikologi, pegawai pemulihan, pekerja social, masyarakat sekeliling serta pihak-pihak yang berkepentingan dalam usaha membantu menjayakan proses pemulihan OKP untuk terus bebas dadah dan dapat menjalani kehidupan dengan sihat dan sejahtera.

\section{Metod Kajian}

Kajian ini menggunakan pendekatan metodologi berbentuk tinjauan keratan-lintang secara kuantitatif. Menurut Malhotra, Sham, \& Crsip (1996), reka bentuk keratan-lintang merupakan 
suatu kaedah yang melibatkan pengumpulan data terhadap satu jenis sampel daripada populasi yang dikaji secara sekali sahaja berdasarkan kepada atribut responden yang sedia ada.

Dalam kajian ini, populasi kajian merujuk kepada klien iaitu OKP yang telah menjalani program CCRC dan kini sedang menjalani program pengawasan di luar institusi. Kesemua mereka yang terlibat dalam kajian terdiri daripada pelbagai kaum, telah tamat mengikuti program rawatan dan pemulihan CCRC dan kini sedang menjalani program pengawasan di luar CCRC melebihi tempoh 6 bulan. Bagi memenuhi kajian ini, sembilan Pusat Pengawasan AADK yang mewakili empat buah lokasi kajian iaitu AADK Kelantan (60 orang), AADK Perak (53 orang), AADK Melaka (48 orang) dan AADK Selangor (57 orang) terlibat dalam kajian. Jumlah keseluruhan mereka yang terlibat dalam kajian ini adalah sejumlah 218 OKP. berikut:

Kajian ini menggunakan set soal selidik yang mengandungi pembolehubah seperti

1. Alat ujian Pengintegrasian Sosial: Alat ujian ini mengandungi enam (40) soalan dengan catatan nilai kebolehpercayaan yang tinggi iaitu 0.978 .

2. Alat ujian Kesihatan Diri: Alat ujian ini mengandungi 19 soalan dengan catatan nilai kebolehpercayaan yang tinggi iaitu 0.809 .

3. Alat ujian Keagamaan: Alat ujian ini mengandungi 32 soalan dengan catatan nilai kebolehpercayaan yang tinggi iaitu 0.954 .

4. Alat ujian Jaminan Pekerjaan: Alat ujian ini mengandungi 16 soalan dengan catatan nilai kebolehpercayaan yang tinggi iaitu 0.844 .

Kesemua soal selidik ini dibangunkan oleh Wan Shahrazad et al., (2018) dengan menggunakan Likert empat poin di mana pilihan-pilihannya disusun mengikut kesesuaian iaitu (1) sangat tidak setuju, (2) tidak setuju, (3) setuju dan (4) sangat setuju.

Penganalisaan data telah dilakukan dengan menggunakan 'Statistical Package for the Sosial Science for Windows' (SPSS for Windows). Data kajian telah dianalisis dengan menggunakan analisis deskriptif untuk mengenalpasti tahap pengintegrasian sosial dalam kalangan OKP. Manakala analisis inferensi dengan menggunakan ujian korelasi digunakan untuk menganalisis hubungan antara kesihatan diri, keagamaan dan jaminan pekerjaan dengan pengintegrasian sosial dalam kalangan OKP. Interpretasi hubungan korelasi ini adalah berdasarkan kepada Guildford's (1973) Rule of Thumb' seperti berikut:

Jadual 1. Interpretasi hubungan korelasi berdasarkan Guildford's (1973) Rule of Thumb'

\begin{tabular}{ll}
\hline Pekali Pearson $(\mathbf{r})$ & Kekuatan Hubungan \\
\hline$<.20$ & Hampir tiada hubungan \\
.20 hingga .40 & Korelasi yang lemah \\
.41 hingga .70 & Korelasi yang sederhana \\
.71 hingga .90 & Korelasi yang kuat \\
$>.90$ & Korelasi yang sangat kuat \\
\hline
\end{tabular}

Nilai $\mathrm{r}$ menunjukkan kekuatan hubungan atau hubungan dua pembolehubah sementara petunjuk - atau + menunjukkan arah hubungan kedua-dua pembolehubah. Semakin tinggi nilai $r$, semakin kuat hubungan pembolehubah tersebut yang ditafsirkan seperti Jadual 1. 
GEOGRAFIA Online ${ }^{\mathrm{TM}}$ Malaysian Journal of Society and Space 16 issue 3 (135-146)

(C) 2020, e-ISSN 2682-7727 https://doi.org/10.17576/geo-2020-1603-11

\section{Hasil Kajian dan Perbincangan}

\section{Profil Orang Kena Pengawasan}

Kajian ini melibatkan sejumlah 218 OKP yang terdiri daripada mereka yang mengikuti program pengawasan di bawah kendalian pihak AADK di negeri Kelantan iaitu sejumlah 60 orang (27.5\%), AADK Melaka iaitu 48 orang (225), AADK Perak iaitu sejumlah 53 orang (24.3\%) dan AADK Selangor iaitu sejumlah 57 orang (26.1\%). Berdasarkan 218 orang OKP tersebut, sejumlah 191 OKP terdiri daripada lelaki (87.6\%) dan enam orang OKP terdiri daripada perempuan $(2.8 \%)$. Mereka yang terlibat dalam kajian ini juga majoritinya terdiri daripada bangsa Melayu iaitu sejumlah 191 orang (87.6\%). Manakala bangsa Cina dan India masingmasing mencatatkan jumlah yang sama untuk setiap bangsa iaitu sejumlah 12 orang (5.5\%) dan masih bujang dan belum berkahwin iaitu sejumlah 115 orang (52.8\%). Manakala selebihnya terdiri daripada mereka yang sudah berkahwin iaitu sejumlah 79 orang (36.2\%), bercerai/sudah berpisah iaitu seramai tujuh orang (3.25) dan berstatus duda/janda iaitu sejumlah 14 orang $(6.4 \%)$.

\section{Tahap Pengintegrasian Sosial OKP}

Hasil analisis deskriptif yang dijalankan terhadap 218 OKP mendapati kebanyakan mereka yang terlibat dalam kajian ini menunjukkan tahap pengintegrasian sosial yang tinggi dan baik iaitu sejumlah 131 OKP bersamaan 60.1\% (Jadual 2). Hasil kajian ini memberi gambaran positif bahawa majoriti OKP yang sedang berada dalam program pengawasan oleh pihak AADK ini dilihat berupaya menyesuaikan diri dengan masyarakat sekeliling mereka. Menurut Wong \& Solomon (2002) pengintegrasian sosial yang berjaya menjadikan seseorang individu merasakan bahawa diri mereka adalah sebahagian daripada ahli komuniti serta berpeluang untuk terlibat dalam interaksi yang bersifat normatif dengan anggota masyarakat bagi mengelak perasaan keterasingan sosial. Gracia dan Herrero (2004) pula berpandangan penerimaan positif daripada persekitaran sosial berupaya membina jaringan sosial yang kuat antara individu dengan anggota masyarakat serta mewujudkan perapatan dengan ahli komuniti agar proses pengintegrasian sosial berjalan dengan jayanya dan memberi implikasi positif terhadap kepulihan.

Jadual 2. Tahap pengintegrasian sosial dalam kalangan OKP $(n=218)$

\begin{tabular}{lrrc}
\hline Tahap & Bilangan OKP & Peratus (\%) & Min \\
\hline Rendah & 2 & 0.9 & \\
Sederhana & 85 & 39.0 & \\
Tinggi & 131 & 60.1 & 3.23 \\
& & & \\
Jumlah & $\mathbf{2 1 8}$ & $\mathbf{1 0 0}$ & \\
\hline
\end{tabular}

Manakala Cullen (1994), Dodge et al. (2001) dan Scroggins (2012) pula menjelaskan bahawa ketersediaan rangkaian sosial dalam komuniti seperti peluang pekerjaan yang tetap, sumber kewangan yang stabil dan kawasan kediaman di tempat yang berisiko rendah membantu proses pengintegrasian sosial bagi bekas pesalah atau penagih dadah. Pengintegrasian sosial yang lemah khasnya ketiadaan sokongan yang baik daripada individu terdekat seperti ahli keluarga hanya akan mencetus kepada tingkah laku penagihan semula dalam kalangan OKP (Fauziah et al., (2017). Kajian yang dijalankan oleh Fauziah (2020) juga mendapati konflik interpersonal 
yang tercetus dalam kalangan ahli keluarga boleh menyebabkan berlakunya tekanan sosial dalam kalangan penagih dadah sehingga menjejaskan kepulihan dan pengintegrasian sosial mereka ke dalam masyarakat.

Menganalisis Hubungan antara Kesihatan Diri, Jaminan Pekerjaan dan Keagamaan dengan Pengintegrasian Sosial Dalam Kalangan Orang Kena Pengawasan:

Hasil ujian korelasi yang telah dijalankan ke atas 218 OKP bagi menganalisis hubungan antara kesihatan diri, jaminan pekerjaan dan keagamaan dengan pengintegrasian sosial dalam kalangan OKP mendapati keputusan kajian seperti Jadual 3.

Jadual 3. Hubungan antara kesihatan diri, jaminan pekerjaan, keagamaan dengan pengintegrasian sosial dalam kalangan OKP.

\begin{tabular}{llrrr}
\hline Pembolehubah & & Kesihatan Diri & Jaminan Pekerjaan & Keagamaan \\
\hline Pengintegrasian & Nilai Korelasi & $.348^{* *}$ & $.485^{* *}$ & $.571^{* *}$ \\
Sosial & Aras Sig. (2- & .000 & .000 & .000 \\
& tailed) & & &
\end{tabular}

$\mathrm{H}_{1}$ : Tidak terdapat hubungan yang signifikan antara kesihatan diri dengan pengintegrasian sosial dalam kalangan OKP

Analisis korelasi mendapati kesihatan diri $\left(\mathrm{r}=.348^{* *}, \mathrm{p}<0.01\right)$, menunjukkan hubungan positif, lemah tetapi signifikan dengan pengintegrasian sosial dalam kalangan OKP. Ini kerana nilai $(p)$ bagi pembolehubah ini kurang daripada aras signifikan .01. Oleh itu dapat dirumuskan bahawa aspek kesihatan diri OKP mempunyai hubungan dengan pengintegrasian sosial. Hubungan positif menunjukkan bahawa semakin tinggi kesihatan diri, maka semakin berjaya pengintegrasian sosial dalam kalangan OKP. Oleh itu, berdasarkan keputusan tersebut, maka kajian ini menolak hipotesis kajian pertama $\left(\mathrm{H}_{1}\right)$ yang meramalkan tidak terdapat hubungan yang signifikan antara kesihatan diri dengan pengintegrasian sosial dalam kalangan OKP

$\mathrm{H}_{2}$ : Tidak terdapat hubungan yang signifikan antara jaminan pekerjaan dengan pengintegrasian sosial dalam kalangan OKP

Analisis kajian mendapati jaminan pekerjaan $\left(\mathrm{r}=.485^{* *}, \mathrm{p}<0.01\right)$, menunjukkan hubungan positif, sederhana dan signifikan dengan pengintegrasian sosial dalam kalangan OKP. Ini kerana nilai $(p)$ bagi pembolehubah ini kurang daripada aras signifikan .01. Oleh itu dapat dirumuskan bahawa aspek jaminan pekerjaan OKP mempunyai hubungan dengan pengintegrasian sosial. Hubungan positif menunjukkan bahawa semakin tinggi jaminan pekerjaan, maka semakin berjaya pengintegrasian sosial dalam kalangan OKP. Oleh itu, berdasarkan keputusan tersebut, maka kajian ini menolak hipotesis kajian kedua $\left(\mathrm{H}_{2}\right)$ yang meramalkan tidak terdapat hubungan yang signifikan antara aspek jaminan pekerjaan dengan pengintegrasian sosial dalam kalangan OKP.

$\mathrm{H}_{3}$ : Tidak terdapat hubungan yang signifikan antara keagamaan dengan pengintegrasian sosial dalam kalangan $O K P$ 
Analisis kajian mendapati keagamaan $\left(\mathrm{r}=.571^{* *}, \mathrm{p}<0.01\right)$, menunjukkan hubungan positif, sederhana dan signifikan dengan pengintegrasian sosial dalam kalangan OKP. Ini kerana nilai $(p)$ bagi pembolehubah ini kurang daripada aras signifikan .01. Oleh itu dapat dirumuskan bahawa aspek keagamaan mempunyai hubungan dengan pengintegrasian sosial dalam kalangan OKP. Hubungan positif menunjukkan bahawa semakin tinggi nilai keagamaan, maka semakin berjaya pengintegrasian sosial dalam kalangan OKP. Oleh itu, berdasarkan keputusan tersebut, maka kajian ini menolak hipotesis kajian ketiga $\left(\mathrm{H}_{3}\right)$ yang meramalkan tidak terdapat hubungan yang signifikan antara aspek keagamaan dengan pengintegrasian sosial dalam kalangan OKP

Jadual 4 menunjukkan ringkasan hasil keputusan ujian korelasi yang dijalankan terhadap ketiga-tiga hipotesis nul kajian yang telah dibentuk. Hasil kajian mendapati ketiga-tiga hipotesis yang dibentuk adalah ditolak dan gagal diterima $\left(\mathrm{H}_{1}, \mathrm{H}_{2}, \mathrm{H}_{3}\right)$.

Jadual 4. Ringkasan hasil ujian korelasi terhadap tiga hipotesis nul kajian $(n=218)$

\begin{tabular}{llcr}
\hline Label & Hipotesis & Keputusan Analisis & Keputusan Hipotesis \\
\hline $\mathrm{H}_{1}$ & $\begin{array}{l}\text { Tidak terdapat hubungan yang signifikan } \\
\text { antara kesihatan diri dengan pengintegrasian } \\
\text { sosial dalam kalangan OKP }\end{array}$ & $\left(\mathrm{r}=.571^{* *}, \mathrm{p}<0.01\right)$, & ${\text { Menolak } \mathrm{H}_{1}}$ \\
\hline $\mathrm{H}_{2}$ & $\begin{array}{l}\text { Tidak terdapat hubungan yang signifikan } \\
\text { antara jaminan pekerjaan dengan } \\
\text { pengintegrasian sosial dalam kalangan OKP }\end{array}$ & $\left(\mathrm{r}=.485^{* *}, \mathrm{p}<0.01\right)$ & $\mathrm{Menolak} \mathrm{H}_{2}$ \\
\hline $\mathrm{H}_{3}$ & $\begin{array}{l}\text { Tidak terdapat hubungan yang signifikan } \\
\text { antara keagamaan dengan pengintegrasian } \\
\text { sosial dalam kalangan OKP }\end{array}$ & $\left(\mathrm{r}=.571^{* *}, \mathrm{p}<0.01\right)$ & ${\text { Menolak } \mathrm{H}_{3}}$ \\
\hline
\end{tabular}

\section{Kesimpulan}

Secara kesimpulan, hasil kajian menunjukkan tahap pengintegrasian sosial dalam kalangan OKP yang berada di bawah pengawasan AADK berada pada tahap yang tinggi dan baik. Keputusan kajian ini memberi ramalan dan petunjuk positif terhadap usaha yang telah dilaksanakan oleh pihak AADK dalam membantu kepulihan OKP. Hasil kajian ini memberi petunjuk bahawa dalam tempoh enam bulan OKP dibebaskan daripada CCRC, mereka dilihat berupaya menyesuaikan diri dengan persekitaran sosialnya dan keadaan ini secara tidak langsung mewujudkan suatu keadaan persekitaran kehidupan yang positif dan memberi kesan yang baik terhadap kejayaan kepulihan. Bagi memantapkan dan meneruskan kelangsungan kepulihan yang berkesan, aspek-aspek seperti kesihatan diri, jaminan pekerjaan dan keagamaan dalam kalangan OKP perlu diberikan perhatian dalam melaksanakan program pengawasan terhadap OKP. Ini bermakna pihak-pihak yang berkepentingan dalam mengurus OKP perlu menyediakan modul berkaitan dengan penjagaan kesihatan diri, membina rangkaian bagi membolehkan OKP mendapatkan pekerjaan dengan industri yang bersesuaian dan memantapkan modul keagamaan bagi membantu kepulihan yang berterusan dan seterusnya membolehkan proses pengintegrasian semula yang baik dalam kalangan OKP. Ketiga-tiga aspek ini adalah penting kerana kajian yang telah dijalankan secara empirikal telah mendapati bahawa ketiga-tiga aspek yang dinyatakan mempamerkan analisis hubungan yang positif dalam membantu menjayakan pengintegrasian sosial dalam kalangan OKP. Ini bermakna semakin tinggi nilai keagamaan, jaminan pekerjaan 
dan kesihatan diri OKP maka semakin baik dan berjaya pengintegrasian sosial mereka ke dalam masyarakat. Pengintegrasian sosial yang berjaya membantu OKP untuk mengadaptasi diri dengan masyarakat sekeliling, membina dan mengukuhkan identiti diri untuk menjadi lebih positif, mampu menghadapi dan menangani masalah keterasingan sosial, mengurangkan risiko relaps dan memberi motivasi ke arah kejayaan kepulihan yang berterusan. Hasil kajian ini secara keseluruhannya memberi implikasi positif terhadap usaha pihak yang berkepentingan dalam membantu mengurangkan masalah dan kadar penagihan semula dalam kalangan OKP.

\section{Penghargaan}

Penghargaan kepada geran Agensi AntiDadah Kebangsaan (AADK) (kod penyelidikan: SK2017-007), Fakulti Sains Sosial dan Kemanusiaan, UKM serta semua yang telah menjayakan kajian ini.

\section{Rujukan}

Agensi Anti Dadah Kebangsaan. (2019). Maklumat Dadah 2017. Kementerian Dalam Negeri. Selangor.

Bracken, D.C., Deane, L. \& Morrissette, K. (2009). Desistance and social marginalization: The case of Canadian aboriginal offenders. Theoretical Criminology, 13(1), 61-78.

Cullen, F.T. (1994). Social support as an organizing concept for criminology: Presidential address to the Academy of Criminal Justice Sciences. Justice Quarterly, 11, 527-559.

Connolly, K., \& Granfield, R. (2017). Building recovery capital: The role of faith-based communities in the reintegration of formerly incarcerated drug offenders. Journal of Drug Issues, 1-13.

Dodge, M., \& Pogrebin, M.R. (2001). Collateral costs of imprisonment for women: Complications of reintegration. The Prison Journal, 81, 42-54.

Eva, J., \& Lennart, S. (2013). Sosial integration as professional field: Psychotherapy in Sweden. School of Sosial Work, Lund University.

Ezarina Zakaria, Fauziah Ibrahim, Salina Nen, Norjana Saim \& Mohd Norahim Mohamed Sani. Perbandingan peluang pekerjaan oleh majikan kepada bekas penagih dadah. (2016). JATI, $21,125-142$.

Fauziah Ibrahim, Ezarina Zakaria, Nor Jana Saim Salina Nen \& Mohd Norahim Mohamed Sani. (2017). Faktor-faktor penyumbang ketahanan diri penagih untuk pulih bebas dadah. Jurnal of Social Sciences and Humanities, 12(1), 060-074.

Fauziah Ibrahim, Ezarina Zakaria, Salina Nen, Norulhuda Sarnon, Nazirah Hassan \& Siti Mariam Murshidan. (2020). Social pressure among former drug addicts after discharged from drug rehabilitation centre. International Journal of Psychosocial Rehabilitation, 24(04), 4517-4525.

Fox, K.J. (2015). Theorizing community integration as desistance-promotion. Criminal Justice and Behaviour, 42(1), 82-94.

Fox, K.J. (2016). Civic commitment: Promoting desistance through community integration. Punishment \& Society Journal, 18(1), 68-94. 
GEOGRAFIA Online ${ }^{\mathrm{TM}}$ Malaysian Journal of Society and Space 16 issue 3 (135-146)

(C) 2020, e-ISSN 2682-7727 https://doi.org/10.17576/geo-2020-1603-11

Gómez, M., Arango, E., Molina, D., \& Barceló, E. (2010). Characteristics of the theory in the sosial behaviour disorder. Journal of the Psychology, 26, 103-118.

Grommon, E. L. (2013). Prisoner re-entry programs: Penetrating the black box for better theory and practice, Vol. 1. El Paso, TX: LFB Scholarly Publishing LLC.

Gracia, E. \& Herrero, J. (2004). Determinants of social integration in the community: An exploratory analysis of personal, interpersonal and situational variables. Journal of Community \& Applied Psychology, 14, 1-15.

Giordano, P.C., Longmore, M.A., Schroeder, R.D. \& Seffrin, P.M. (2007). A life course perspective on spirituality and desistance from crime. Center for Family and Demographic Research, Working Paper Series 07-07.

Irin, J. (1970). The Felon. Englewood Cliffs, NJ: Prentice Hall.

Law, F.M \& Guo, G.J. (2012). Hope and recovery from substance abuse for female drug offenders in Taiwan. International Journal of Offender Therapy and Comparative Criminology, 56 (8), 1258-1282.

Leverentz, A. (2011). Neighborhood context of attitudes toward crime and reentry. Punishment \& Society Journal, 13(1), 64-92. DOI: 10.1177/1462474510385629

Lopez, F., Carpintero, E., Campo, A., Lazaro, S., \& Soriano, S. 2011. Program for Juvenile Offenders: Educational and Therapeutic Intervention. Madrid: Pirámide.

Jacobs, J. (2013). The liberal polity, criminal sanction, and civil society. Criminal Justice Ethics, 32, 231-246.

Juan, M.F.C., \& José, M.A.P. (2017). Study to investigate the links between crimes committed by youth offenders and the nature of their migratory movements. Procedia - Social and Behavioral Sciences, 237, 505-510.

Malhotra, N.K., Hall, J., Sham, M \& Crsip, M. (1996). Marketing research: Applied orientation (1st Edition). Sydney: Prentice Hall.

McNeill, F. (2014). How best to stop offenders reoffending and reintegrate them into civil society. British Academy London. SAGE Publications.

Mohd Alif Jasni, Siti Hajar Abu Bakar Ah, Jal Zabdi Mohd Yusoff, Khariyah Md. Shahid, Noralina Omar \& Zaiton Azman. (2018). Faktor penghijrahan dan penumpuan bekas banduan di Jalan Chow Kit, Kuala Lumpur. Geografia-Malaysian Journal of Society and Space, 14(1), 87-101.

Scroggins, Jennifer Rhiannon. (2012). Gender, sosial ties and re-entry experiences. University of Tennessee.

Tharshini Sivabalan, Fauziah Ibrahim, Mohd Suhaimi Mohamad, \& Ezarina Zakaria. (2018). Tahap konsep kendiri, kesedaran komuniti, sokongan sosial dan pengintegrasian sosial bagi pesalah muda di Malaysia. Jurnal Akademika, 88(3), 91-100.

Tharshini Sivabalan \& Fauziah Ibrahim. (2018). Faktor-faktor pelindung yang menyumbang ke arah pengintegrasian semula banduan yang berjaya: Satu kajian ulasan sistematik. Journal of Advanced Research in Social and Behavioural Sciences, 12(1), 54-63.

Travis, J., \& Waul, M. (2003). Prisoners once removed: The impact of incarceration and reentry on children, families and communities. Washington, DC: Urban Institute.

Uggen, C. (2000). Work as a turning point in the life course of criminals: A duration model of age, employment and recidivism. American Sociological Review, 65(4), 529-546.

Uggen, C., Wakefield, S. \& Western, B. (2005). Work and family perspectives on re-entry. In Travis, J. \& Visher, C. (Eds.), Prisoner re-entry and crime in America, pp. 209-243. New York: Cambridge University Press 
Waleed, Craig A. (2010). Individually perceived supports and barriers to successful community re-entry after serving a prison sentence. Counsellor Education Master's Theses. The College at Brockport.

Wong, Y.I. \& Solomon, P.L. (2002). Community integration of persons with psychiatric disabilities in supportive independent housing: A conceptual model and methodological considerations. Mental Health Services Research, 4, 13-28.

Zarina Othman, Nor Azizan Idris \& Mohamad Daud Druis. (2015). Penyalahgunaan dadah sebagai ancaman keselamatan: Analisis keberkesanan program kerajaan dalam mengekang pengrekrutan penagih dadah di Malaysia. Geografia-Malaysian Journal of Society and Space, 11(13), 60-71. 